\title{
Ion Migration in Metal Halide Perovskites
}

\author{
Anafi Nur'aini ${ }^{2,3}$, Seokwon Lee ${ }^{1}$, and Ilwhan $\mathrm{Oh}^{1,3 *}$ \\ ${ }^{1}$ Departments of Applied Chemistry, Kumoh National Institute of Technology, Gumi, Gyeongbuk, 39177 South Korea \\ ${ }^{2}$ Chemical Engineering, Kumoh National Institute of Technology, Gumi, Gyeongbuk, 39177 South Korea \\ ${ }^{3}$ Department of Energy Convergence Engineering, Kumoh National Institute of Technology, Gumi, Gyeongbuk, 39177 South Korea
}

\begin{abstract}
Metal halide perovskites are promising photovoltaic materials, but they still have some issues that need to be solved. Hysteresis is a phenomenon that strongly is correlated with ion migration; thus, a fast, easy, and low-temperature method for measuring ion migration is required. Through selective blocking, ion migration can be measured separately, apart from electron migration. In this study, ion migration in metal halide perovskites was measured using a vertical device. At different temperatures, ionic activation energies were obtained for a range of perovskite compositions such as $\mathrm{MAPbI}_{3}, \mathrm{FAPbI}_{3}, \mathrm{CsP}-$ $\mathrm{bI}_{3}$, and $\mathrm{MAPbBr}_{3}$. By comparing the measured ionic activation energies with the theoretical values, we conclude that among other possibilities, $\mathrm{I}^{-}$is the migrating ion in $\mathrm{MAPbI}_{3}, \mathrm{FAPbI}_{3}, \mathrm{CsPb}_{3}$, and $\mathrm{Br}^{-}$is the migrating in $\mathrm{MAPbBr}_{3}$.
\end{abstract}

Keywords : Ion Migration, Activation Energy, Perovskite, Selective Blocking

Received : 28 January 2021, Accepted : 8 June 2021

\section{Introduction}

In 2009, for the first time, metal halide perovskite film was introduced as a solar absorber into dye-sensitized solar cells. At that time, device efficiency was only $3.8 \%$ [1]. Perovskite has been intensively developed into higher efficiency due to its high potential for solar energy converter and easy fabrication. Recently, perovskite has successfully achieved an efficiency of $25.2 \%$ [2]. Even though perovskite can attain high efficiency, its stability during long operation remains an issue $[3,4]$. Stability is one of the gold standards for commercialization of photovoltaic devices.

Investigations into perovskite characteristics have shown some anomalies, such as slow photocurrent response [5], switchable photocurrent [6], and hysteresis $[4,7]$. Hysteresis is a common phenomenon when the shape of the current-voltage ( $I-V)$ graph differs between forward and backward scans. This phenomenon leads to low performance and efficiency degradation [8,9]. Previous studies have identified

*E-mail address: ioh@kumoh.ac.kr

DOI: https://doi.org/10.33961/jecst.2021.00136

This is an open-access article distributed under the terms of the Creative Commons Attribution Non-Commercial License (http://creativecommons.org/licenses/by-nc/4.0) which permits unrestricted non-commercial use, distribution, and reproduction in any medium, provided the original work is properly cited. that hysteresis is caused by scan speed [6], film fabrication and crystallinity [8,9], charge trapping [10], ferroelectricity [11], and ion migration $[4,6,11]$. Because perovskite conducts both electrons and ions, thus ion transport may become an issue. However, because the electron and ion conduction are mixed, it is difficult to measure ion conduction quantitatively.

Several experimental techniques have been used to discover evidence of ion migration, such as photo thermal-induced resonance microscopy (PTIR) [12], Tubandt method [13], impedance spectroscopy [14], time of flight secondary ion mass spectrometry (TOF-SIMS) [15], electrochemical, and selective blocking $[16,17]$. Selective blocking measurement is easily accomplished and can be conducted at low temperatures. This method allows the separation of ion conduction from total conductivity [16]. A constant current is applied to measure the steady-state of voltage as a function of time; thus, electron and ion conductivity can be extracted [17]. Initially, both ions and electrons pass through the perovskite film. Then, the number of passing ions is reduced until only electrons directly pass through the perovskite film (Fig. 1a) [16].

In this study, ionic activation energies of the perovskite films $\mathrm{MAPbI}_{3}, \mathrm{FAPbI}_{3}, \mathrm{CsPbI}_{3}$, and $\mathrm{MAPb}$ $\mathrm{Br}_{3}$, were measured using the selective blocking 
a)
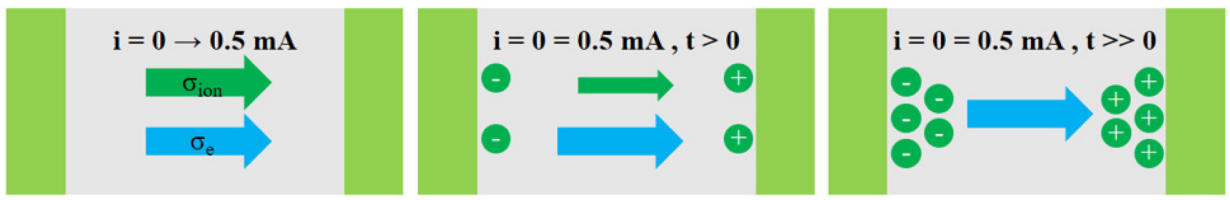

b)

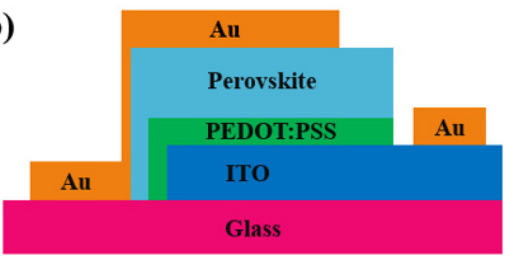

Fig. 1. (a) Schematic diagram of selective blocking measurement, (b) Structure of vertical device used in this study.

method. Ionic activation energy is influenced by crystal structure, radius of ion, and charge of ion [4]. For $\mathrm{MAPbI}_{3}$, the migrating ions might be $\mathrm{I}^{-}, \mathrm{Pb}^{2+}$, $\mathrm{MA}^{+}$, or $\mathrm{H}^{+}[4,18]$. If cation $\mathrm{MA}^{+}$is substituted into $\mathrm{FA}^{+}$and $\mathrm{Cs}^{+}$, these ions may also migrate in the perovskite film. The ion migration in $\mathrm{FAPbI}_{3}$ can be suppressed by $\mathrm{FA}^{+}$, which has a larger diameter than $\mathrm{MA}^{+}$[15]. Substitution of $\mathrm{MA}^{+}$with monovalent cation $\mathrm{Cs}^{+}$can eliminate the effects of ion migration enhancement due to light intensity in $\mathrm{MAPbI}_{3}[17]$. Anion substitution of $\mathrm{I}^{-}$into $\mathrm{Br}^{-}$may provide another insight because $\mathrm{Br}^{-}$is also predicted to play a role in ion migration. Understanding ion migration makes it possible to design a new strategy to improve the stability of perovskites film.

\section{Experimental}

\subsection{Fabrication of vertical devices}

The structure of a vertical device is illustrated in Fig. 1b. This sandwich-like structure consisted of indium tin oxide (ITO), poly-(3,4-ethylene dioxythiophene): poly(styrene sulfonic acid) (PEDOT: PSS), a perovskite film, and gold. ITO glass was cut into $1 \times 1$ inch. A distance of $7 \mathrm{~mm}$ from one of the edges was etched using $\mathrm{Zn}$ powder and $\mathrm{HCl}$ solution to remove the ITO layer. ITO glass was cleaned by sonication in acetone, isopropyl alcohol, and deionized water for $10 \mathrm{~min}$ each. The cleaning process was continued by oxygen plasma for $20 \mathrm{~min}$ to improve the adhesion between the substrate and thin film.

PEDOT: PSS was filtered using $0.45 \mu \mathrm{m}$ syringe filter then spin-coated onto clean ITO at $4000 \mathrm{rpm}$ for $15 \mathrm{~s}$ and ramp 5.0. PEDOT: PSS layer was dried on the hot plate for $15 \mathrm{~min}$ at $125^{\circ} \mathrm{C}$. The deposition pro- cess was performed in ambient air. On the top of PEDOT: PSS layer, perovskite solution $\left(\mathrm{MAPbI}_{3}\right.$, $\mathrm{MAPbBr}_{3}, \mathrm{FAPbI} 3$, or $\mathrm{CsPbI}_{3}$ ) was spin-coated at $1000 \mathrm{rpm}$ for $40 \mathrm{~s}$, ramp 5.0, and $5000 \mathrm{rpm}$ for $20 \mathrm{~s}$. During spin-coating of $\mathrm{MAPbI}_{3}, \mathrm{FAPbI}_{3}, \mathrm{CsPbI}_{3}$, at $t=64 \mathrm{~s}, 800 \mu \mathrm{L}$ of toluene was dropped on the top of perovskite film. For $\mathrm{MAPbBr}_{3}$, the toluene was dropped at $t=57 \mathrm{~s}$. Toluene acted as an antisolvent for precursor; therefore, toluene drip facilitated fast crystallization of perovskite film. The perovskite film was dried on the hot plate for $10 \mathrm{~min}$ at $100^{\circ} \mathrm{C}$ for $\mathrm{MAPbI}_{3}$, $170^{\circ} \mathrm{C}$ for $\mathrm{FAPbI}_{3}, 350^{\circ} \mathrm{C}$ for $\mathrm{CsPbI}_{3}$, and $75^{\circ} \mathrm{C}$ for $\mathrm{MAPbBr}_{3}$. The deposition process was conducted under $\mathrm{N}_{2}$ gas inside a glove box. Finally, an $80 \mathrm{~nm} \mathrm{Au}$ layer was deposited on the top of the perovskite layer using a thermal evaporator at a rate of $1 \AA / \mathrm{s}$.

\subsection{Sample characterization}

$\mathrm{X}$-ray diffraction measurements (XRD) were carried out using Rigaku X-MAX from $10^{\circ}-40^{\circ}$ to examine the structure of each perovskite material. The vertical structure of each sample was confirmed by cross-section observation using Field Emission Scanning Electron Microscope (FE-SEM) MAIA III TESCAN and JEOL JSM-6701F.

\subsection{Selective blocking measurement}

Selective blocking measurements were performed by a four-point probe system with a Faraday cage and a black shield. The black shield provided a dark condition for the measurement because, in this condition, ions migrate faster than electrons. The four-point probes were connected to the AutoLab controller with the PGSTAT302N module. NOVA Metrohm Autolab B.V version 1.10.1.9 was used as software. 
During measurement, two probes were connected to the cell. Hot chuck MH4R and controller MST $1000 \mathrm{H}$ were used to control the temperature of the sample. Chronopotentiometry $(\Delta t>1 \mathrm{~ms})$ was used to characterize the sample in a $100 \mathrm{nA}$ current flow for $20 \mathrm{~s}$. The voltage-time $(V-t)$ curve from that measurement was then used to calculate total resistance and electronic resistance. Finally, the resistivity and conductivity of both electrons and ions can be obtained.

\section{Results and Discussions}

\subsection{Characterization of materials and devices}

$\mathrm{X}$-ray diffraction measurements were conducted to examine the perovskite structure. Each perovskite solution was deposited onto ITO or FTO glass without Au and PEDOT: PSS layer. The structure of each perovskite is presented in Fig. 2a-d. Fig. 2a shows (110), (220), and (310) peaks corresponding to the formation of orthorhombic $\mathrm{MAPbI}_{3}[19,20]$. Fig. 2b confirms the formation of $\mathrm{FAPbI}_{3}$, showing (101), (202), and (211) peaks, which are assigned to trigonal $\alpha-\mathrm{FAPbI}_{3}$ or black phase $\mathrm{FAPbI}_{3}[21,22]$. Fig. $2 \mathrm{c}$ shows maximum intensity for (100) and (200), indicating the cubic black phase of $\mathrm{CsPbI}_{3}$, and the lower peak (110) indicates strain in the crystal structure $[23,24]$. In Fig. 2d, peaks of (100) and (200) correspond to $\mathrm{MAPbBr}_{3}$ with cubic formation [25].

FE-SEM confirmed the vertical structure of the device. The devices were constructed like a sandwich (ITO/PEDOT: PSS/perovskite/Au) with perovskite as an active layer. FE-SEM images are presented in Fig. 3a-d.

Cross-section images show that all layers are presented and vertically stacked. The perovskite thickness was approximately $200 \mathrm{~nm}$. Using the Scherrer equation, average grain size can be calculated from XRD peaks. The average grain size for $\mathrm{MAPbI}_{3}$ is $43 \pm 3 \mathrm{~nm} . \mathrm{CsPbI}_{3}$ has a larger grain size of $51 \pm$ $4 \mathrm{~nm} . \mathrm{MAPbBr}_{3}$ has the largest average grain size $(55 \pm 4 \mathrm{~nm})$, whereas $\mathrm{FAPbI}_{3}$ has the smallest average grain size $(29 \pm 7 \mathrm{~nm})$. These average grain sizes are much lower than other groups whose minimum grain sizes are approximately $300 \mathrm{~nm}[26,27]$.

However, grain size is correlated to the grain boundaries. Small grain sizes lead to extensive grain boundaries vice versa. Because grain boundaries facilitate the ion migration pathway [4], ion migration is easier in the film with small grain sizes [6]. a)

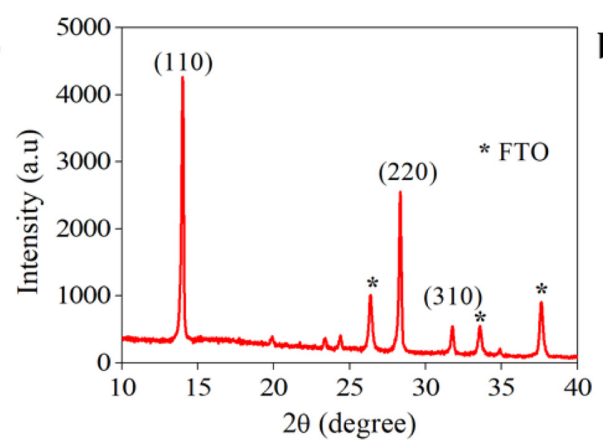

c)

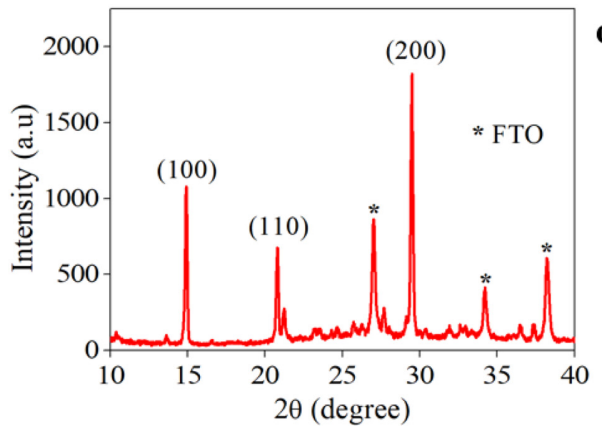

b)

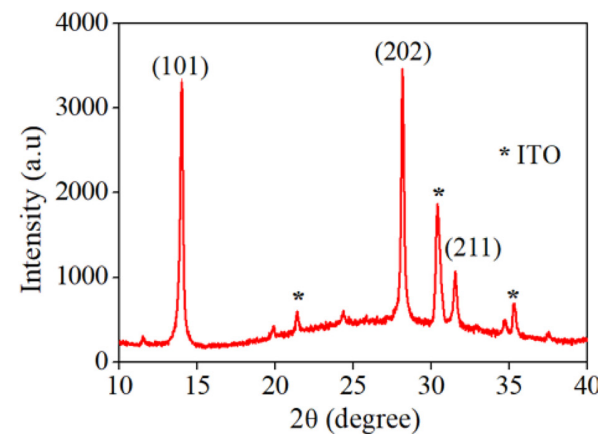

d)

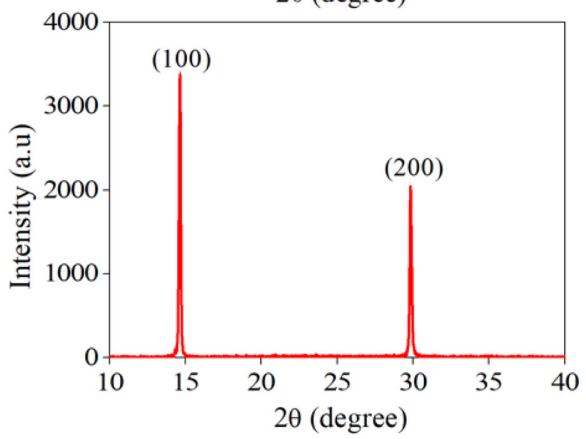

Fig. 2. XRD patterns of (a) $\mathrm{MAPbI}_{3}$, (b) $\mathrm{FAPbI}_{3}$, (c) $\mathrm{CsPbI}_{3}$, and (d) $\mathrm{MAPbBr}_{3}$. 
a)

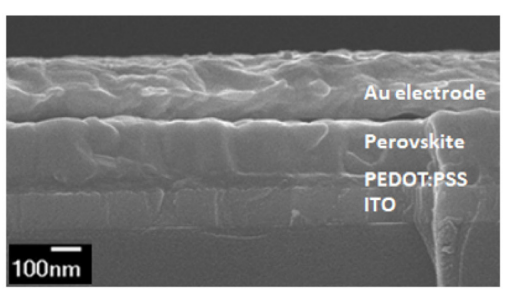

c)

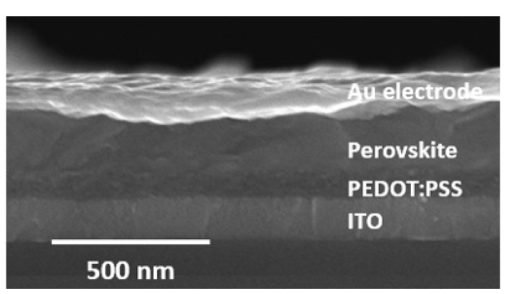

b)

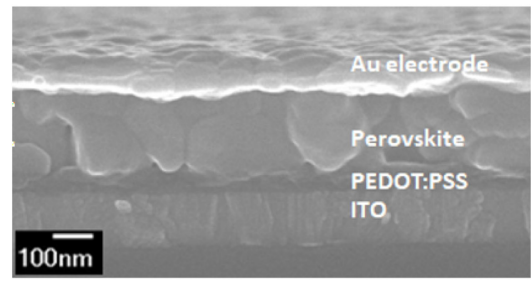

d)

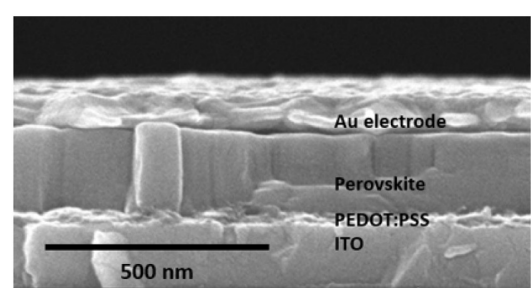

Fig. 3. FE-SEM cross sections of (a) $\mathrm{MAPbI}_{3}$, (b) $\mathrm{FAPbI}_{3}$, (c) $\mathrm{CsPbI}_{3}$, and (d) $\mathrm{MAPbBr}_{3}$.

\subsection{Selective blocking}

Selective blocking measurements were performed in the dark, and ionic conductivities were measured. When a constant current was applied to the vertical device, the potential difference between two terminals was measured as a function of time. The potential difference was affected by electronic resistance $\left(R_{e}\right)$ and ionic resistance $\left(R_{\text {ion }}\right)$, which can be written as Eqn. (1) [13]:

$$
V=i \frac{R_{e} R_{i o n}}{R_{e}+R_{\text {ion }}}
$$

As ions keep migrating in one direction, the ions were depleted at one end and accumulated at another end. In this stage, only electrons migrated, which correspond to $i=i_{e}$ and $i_{\text {ion }}=0$ [13]. Thus, the voltage can be written as Eqn. (2) :

$$
V=i R_{e}
$$

By measuring the initial and final voltages, and combining Eqn. (1) and (2), $R_{e}$ and $R_{\text {ion }}$ can be determined. Furthermore, the ionic $\left(\sigma_{i o n}\right)$ and electronic conductivities $\left(\sigma_{e}\right)$ can be calculated from $R_{i o n}$ and $R_{e}$. In this study, each sample was measured at room temperature $\left(20-40^{\circ} \mathrm{C}\right)$, which perovskite devices operate typically.

Fig. 4a-d show the voltage-time $(V-t)$ graphs from selective blocking measurements for various perovskite materials, which show typical behavior of mixed conduction of electrons and ions. At the current onset, perovskite film exhibits a lower resistance because both ionic and electronic conduction occurs. However, as the ionic conduction is blocked at the interface between the perovskite and metal electrode, the resistance is gradually increased and reaches a steady-state level, where ionic conduction is completely blocked, and only electrons can flow. On the other hand, when the temperature is increased, the resistance of the perovskite is decreased because charge carriers (electrons and ions) are thermally activated. Using the Arrhenius relation between the conductivity and temperature, the activation energy $\left(E_{a}\right)$ for conduction can be obtained as shown in Fig. 5a-d.

\subsection{Ionic activation energy}

Activation energy $\left(E_{a}\right)$ is the minimum energy that must be overcome by an ion to jump from its initial position to nearby vacancy sites [26]. After calculating ionic conductivities at each temperature, these values can be further processed to extract the $E_{a}$ value for each perovskite materials. Following Arrhenius dependence, ionic activation energy can be calculated using Eqn. (3) [17]:

$$
\sigma_{i} T=\sigma_{0} \exp \left[\frac{E_{a}}{k_{b} T}\right]
$$

where $\sigma_{i}$ is conductivity, $\sigma_{0}$ is the pre-exponential factor, $E_{a}$ is the activation energy, $k_{b}$ is Boltzmann constant, and $T$ is temperature. That equation can be 
a)

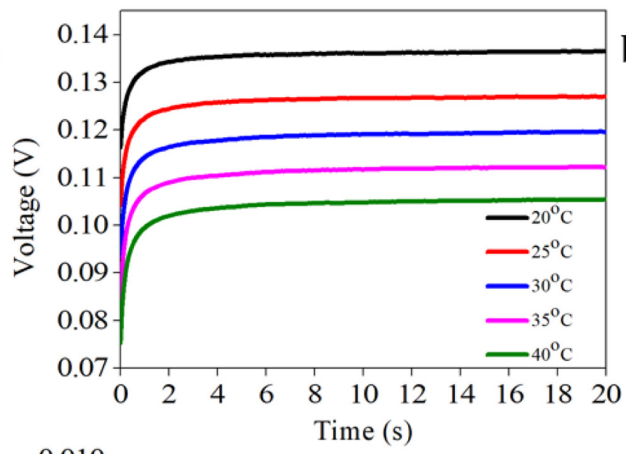

c)

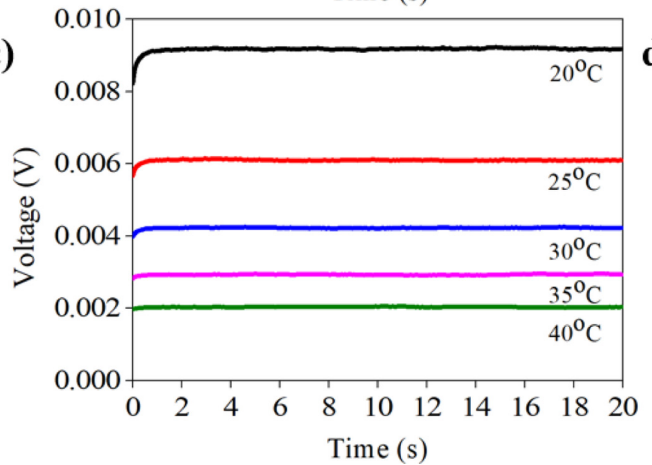

b)

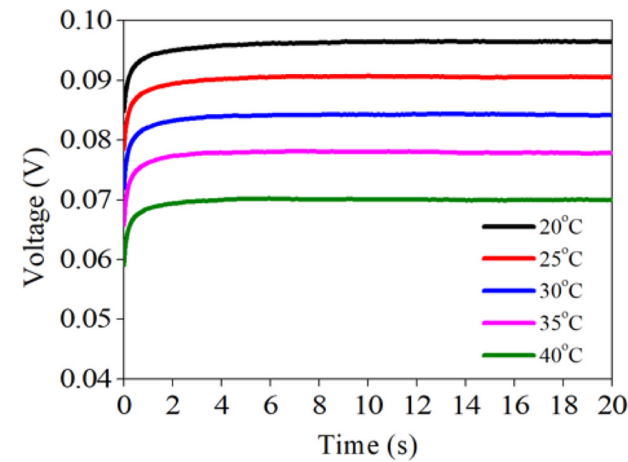

d)

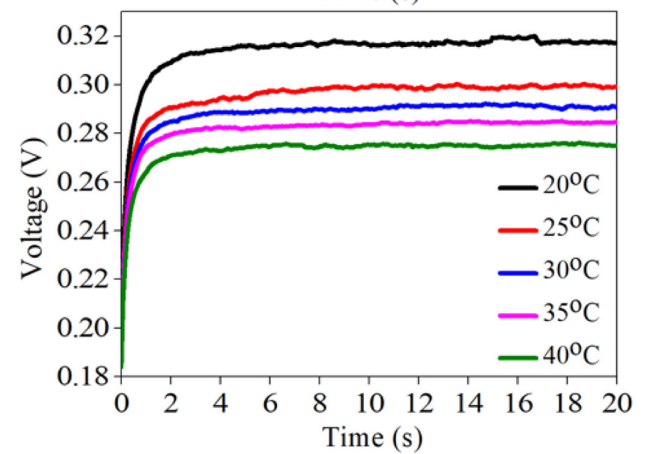

Fig. 4. $V$ - $t$ graphs from selective blocking measurements for (a) $\mathrm{MAPbI}_{3}$, (b) $\mathrm{FAPbI}_{3}$, (c) $\mathrm{CsPbI}_{3}$, and (d) $\mathrm{MAPbBr}_{3}$.
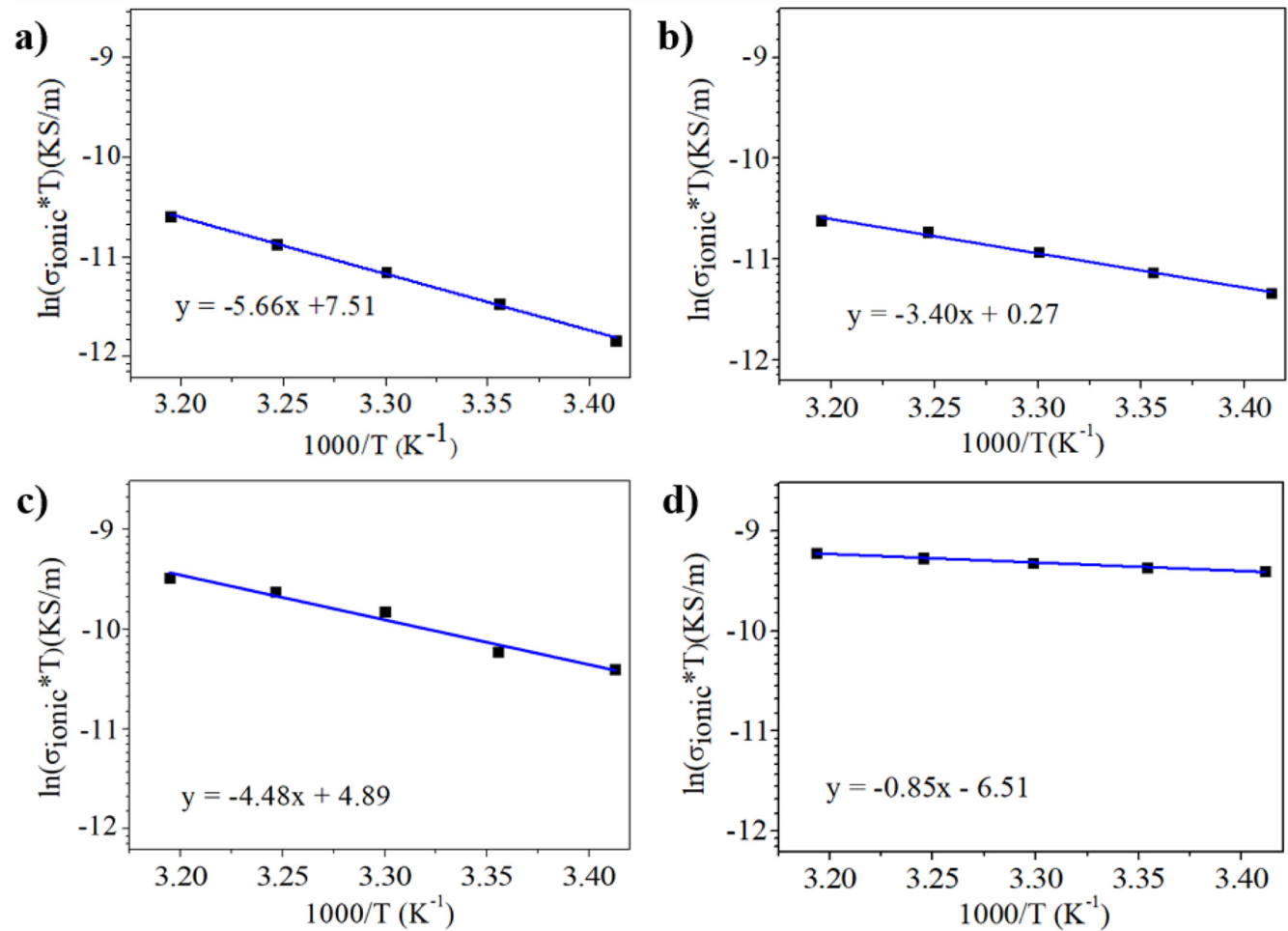

Fig. 5. Arrhenius plots of ionic conductivities for (a) $\mathrm{MAPbI}_{3}$, (b) $\mathrm{FAPbI}_{3}$, (c) $\mathrm{CsPbI}_{3}$, and (d) $\mathrm{MAPbBr}_{3}$. 
Table 1. Ionic activation energy $\left(E_{a}\right)$ of various perovskite materials

\begin{tabular}{cccc}
\hline \hline Perovskite materials & $E_{a}$ from our experiments $(\mathrm{eV})$ & $E_{a}$ from previous studies $(\mathrm{eV})$ & Ionic radius $(\mathrm{nm})$ \\
\hline $\mathrm{MAPbI}_{3}$ & $0.48 \pm 0.01$ & $0.43[13], 0.45[28], 0.58[29]$ & $0.220(\mathrm{I}) 0.216\left(\mathrm{MA}^{+}\right)$ \\
$\mathrm{MAPbBr}_{3}$ & $0.073 \pm 0.004$ & $0.25[20], 0.09[30]$ & $0.196\left(\mathrm{Br}^{-}\right)$ \\
$\mathrm{FAPb}_{3}$ & $0.29 \pm 0.01$ & $0.6[32], 0.48,0.55[33]$ & $0.253\left(\mathrm{FA}^{+}\right)$ \\
$\mathrm{CsPb}_{3}$ & $0.38 \pm 0.03$ & $0.36[34], 0.53[35]$ & $0.167\left(\mathrm{Cs}^{+}\right)$ \\
\hline
\end{tabular}

rearranged into Eqn. (4):

$$
\ln \left(\sigma_{i} T\right)=\ln \left(\sigma_{o}\right)+\left[-\frac{E_{a}}{k_{b} T}\right]
$$

In Fig. $5 \ln \left(\sigma_{i} T\right)$ versus $1 / T$ is plotted, and a linear fit is applied. The slope corresponds to $-\frac{E_{a}}{k_{b}}$, from which $E_{a}$ value can be determined. The $E_{a}$ value of $\mathrm{MAPbI}_{3}, \mathrm{MAPbBr}_{3}, \mathrm{FAPbI}_{3}$, and $\mathrm{CsPbI}_{3}$ are $0.49 \mathrm{eV}$, $0.07 \mathrm{eV}, 0.29 \mathrm{eV}$, and $0.39 \mathrm{eV}$, respectively. These values are presented in Table 1 and compared with other studies to analyze the possible migrating ions in the perovskite.

The measured $E_{a}$ value for $\mathrm{MAPbI}_{3}(0.48 \mathrm{eV})$ is close to those from previous literature, which is $0.43 \mathrm{eV}$ [13] and $0.45 \mathrm{eV}$ [28]. According to a study using density functional theory (DFT) calculation, the activation energy of $\mathrm{I}^{-}$is $0.58 \mathrm{eV}$ [29]. It is assumed that $\mathrm{I}^{-}$has the shortest pathway to $\mathrm{I}^{-}$vacancies through the edge of $\mathrm{PbI}_{6}$ octahedron. In contrast, $\mathrm{Pb}^{2+}$ has the longest pathway because it needs to pass along the diagonal direction $<110>$. Meanwhile, $\mathrm{MA}^{+}$migrates to the nearest $\mathrm{V}^{\prime}{ }_{\mathrm{MA}}$ cage of the unit cell face composed of four I ions. Both $\mathrm{Pb}^{2+}$ and $\mathrm{MA}^{+}$ have longer paths than $\mathrm{I}^{-}$; thus $\mathrm{Pb}^{+}(2.31 \mathrm{eV})$ and $\mathrm{MA}^{+}(0.84 \mathrm{eV})$ have higher activation energies than $\mathrm{I}^{-}$ $(0.58 \mathrm{eV})$ [29].

The $E_{a}$ value for $\mathrm{MAPbBr}_{3}(0.073 \mathrm{eV})$ in Table 1 has important implications in identifying the migrating species in the perovskite materials. With the substitution of $\mathrm{I}^{-}$with $\mathrm{Br}^{-}, \mathrm{MAPbBr}_{3}$ has a much lower $E_{a}$ value than $\mathrm{MAPbI}_{3}(0.48 \mathrm{eV})$. The lowered $E_{a}$ for the anion -substituted perovskite indicates that the migrating species might be the anion. As the ionic radius of $\mathrm{Br}^{-}(0.196 \mathrm{~nm})$ is smaller than $\mathrm{I}^{-}(0.220 \mathrm{~nm})$, $\mathrm{Br}^{-}$will more easily migrate in the perovskite crystal despite the lattice size of the $\mathrm{Br}^{-}$substituted perovskite in smaller than generic material. In contrast, other groups suggested that according to computational study, $\mathrm{Br}^{-}$has comparable energy activation to

\section{$\mathrm{I}^{-}[30,31]$.}

In this study, we also investigated cation substitution by substituting $\mathrm{MA}^{+}$with $\mathrm{FA}^{+}$and $\mathrm{Cs}^{+}$. The experimental result showed that $\mathrm{FAPbI}_{3}(0.29 \mathrm{eV})$ has lower ionic activation energy than $\mathrm{MAPbI}_{3}$ $(0.48 \mathrm{eV})$. Noting that $\mathrm{FA}^{+}(0.253 \mathrm{~nm})$ is larger than $\mathrm{MA}^{+}(0.216 \mathrm{~nm})$, the observed reduction of $E_{a}$ value for $\mathrm{FAPbI}_{3}$ can be explained by the fact that $\mathrm{FAPbI}_{3}$ has a larger lattice constant, leading to a lower barrier for I migration. For $\mathrm{CsPb}_{3}$, even though the ionic radius of $\mathrm{Cs}^{+}$is smaller than $\mathrm{MA}^{+}$and the smaller crystal might increase the barrier for $\mathrm{I}^{-}$migration, the measured $E_{a}$ value is smaller than that for $\mathrm{MAPbI}_{3}$. This result is not clearly understood yet. We expect that other factors than crystal lattice size might come into play, such as simultaneous cation $\left(\mathrm{Cs}^{+}\right)$migration or ion migration along the grain boundary.

In this experiment, a perovskite film was fabricated by a solution process followed by annealing, which allowed evaporation of solvent after spin coating. Consequently, grain boundaries were generated on the surface, which might have facilitated ion migration. If the ion migrates in the grain boundaries, the ionic activation energy is only half of the ionic activation energy from ion migration in bulk [4]. Therefore, the low ionic activation energy of metal halide perovskite in this experiment compared to others might have been caused by the abundance of grain boundaries.

\section{Conclusions}

Ion migration in metal halide perovskite was investigated by measuring ionic activation energy. The ionic activation energies from the vertical structure devices of $\mathrm{MAPbI}_{3}, \mathrm{MAPbBr}_{3}, \mathrm{FAPbI}_{3}$, and $\mathrm{CsPbI}_{3}$ were examined using selective blocking. The ionic conductivity was extracted from mixed conductivity at $20^{\circ} \mathrm{C}$ to $40^{\circ} \mathrm{C}$. The calculated ionic activation energy from $\mathrm{MAPbI}_{3}, \mathrm{FAPbI}_{3}, \mathrm{CsPbI}_{3}$, and $\mathrm{MAPb}$ $\mathrm{Br}_{3}$, are $0.49 \mathrm{eV}, 0.29 \mathrm{eV}, 0.39 \mathrm{eV}$, and $0.07 \mathrm{eV}$, 
respectively. These values were compared with other results in the literature. Variations in ionic activation energy are understandable because every research group has different experimental techniques, fabrication processes, and measurement conditions. This study found that $\mathrm{I}^{-}$is a possible ion that migrates in $\mathrm{MAPbI}_{3}, \mathrm{FAPbI}_{3}$, and $\mathrm{CsPbI}_{3}$, whereas $\mathrm{Br}^{-}$is the most mobile ion in $\mathrm{MAPbBr}_{3}$.

\section{Acknowledgments}

This research was supported by the sabbatical of Kumoh National Institute of Technology.

\section{References}

[1] A. Kojima, K. Teshima, Y. Shirai, and T. Miyasaka, $J$. Am. Chem. Soc., 2009, 131(17), 6050-6051.

[2] N. R. E. L. (NREL), http://www.nrel.gov/ncpv/images/ efficiency_chart.jpg. 2016.

[3] L. Meng, J. You, and Y. Yang, Nat. Commun., 2018, 9(1), 1-4.

[4] Y. Yuan and J. Huang, Acc. Chem. Res., 2016, 49(2), 286-293.

[5] W. Nie, J. C. Blancon, A. J. Neukirch, K. Appavoo, H. Tsai, M. Chhowalla, M. A. Alam, M. Y. Sfeir, C. Katan, J. Even, S. Tretiak, J. J. Crochet, G. Gupta, and A. D. Mohite, Nat. Commun., 2016, 7(1), 1-9.

[6] Z. Xiao, Y. Yuan, Y. Shao, Q. Wang, Q. Dong, C. Bi, P. Sharma, A. Gruverman, and J. Huang, Nat. Mater. 2015, 14(2), 193-197.

[7] H. J. Snaith, A. Abate, J. M. Ball, G. E. Eperon, T. Leijtens, N. K. Noel, S. D. Stranks, J. T. W. Wang, K. Wojciechowski, and W. Zhang, J. Phys. Chem. Lett., 2014, 5(9), 1511-1515.

[8] H. S. Kim and N. G. Park, J. Phys. Chem. Lett., 2014, 5(17), 2927-2934.

[9] Y. Shao, Z. Xiao, C. Bi, Y. Yuan, and J. Huang, Nat. Commun., 2014, 5(1), 1-7.

[10] S. H. Kim and D. Lee, J. Phys. Chem. C., 2019, 123(14), 9629-9633.

[11] T. Zhang, H. Chen, Y. Bai, S. Xiao, L. Zhu, C. Hu, Q. Xue, and S. Yang, Nano Energy., 2016, 26, 620-630.

[12] Y. Yuan, J. Chae, Y. Shao, Q. Wang, Z. Xiao, A. Centrone, and J. Huang, Adv. Energy Mater., 2015, 5(15), 1500615.

[13] T. Y. Yang, G. Gregori, N. Pellet, M. Grätzel, and J. Maier, Angew. Chemie - Int. Ed., 2015, 54(27), 79057910.

[14] D. Klotz, G. Tumen-Ulzii, C. Qin, T. Matsushima, and C. Adachi, RSC Adv, 2019, 9(57), 33436-33445.

[15] T. Zhang, X. Meng, Y. Bai, S. Xiao, C. Hu, Y. Yang, H. Chen, and S. Yang, J. Mater. Chem. A., 2017, 5(3), 1103-1111.
[16] Y. C. Zhao, W. K. Zhou, X. Zhou, K. H. Liu, D. P. Yu, and Q. Zhao, Light Sci. Appl., 2017, 6(5), e16243e16243.

[17] W. Zhou, Y. Zhao, X. Zhou, R. Fu, Q. Li, Y. Zhao, K. Liu, D. Yu, and Q. Zhao, J. Phys. Chem. Lett., 2017, 8(17), 4122-4128.

[18] D. A. Egger, L. Kronik, and A. M. Rappe, Angew. Chem. Int. Ed., 2015, 54(42), 12437-12441.

[19] G. Jang, H. C. Kwon, S. Ma, S. C. Yun, H. Yang, and J. Moon, Adv. Energy Mater, 2019, 9(36), 1901719.

[20] L. J. Phillips, A. M. Rashed, R. E. Treharne, J. Kay, P. Yates, I. Z. Mitrovic, A. Weerakkody, S. Hall, and K. Durose, Sol. Energy Mater. Sol. Cells., 2016, 147, 327333.

[21] L. K. Ono, E. J. Juarez-Perez, and Y. Qi, ACS Appl. Mater. Interfaces., 2017, 9(36), 30197-30246.

[22] G. E. Eperon, D. Bryant, J. Troughton, S. D. Stranks, M. B. Johnston, T. Watson, D. A. Worsley, and H. J. Snaith, J. Phys. Chem. Lett., 2015, 6(1), 129-138.

[23] Y. G. Kim, T. Y. Kim, J. H. Oh, K. S. Choi, Y. J. Kim, and S. Y. Kim, Phys. Chem. Chem. Phys., 2017, 19(8), 6257-6263.

[24] G. E. Eperon, G. M. Paternò, R. J. Sutton, A. Zampetti, A. A. Haghighirad, F. Cacialli, and H. J. Snaith, J. Mater. Chem. A., 2015, 3(39), 19688-19695.

[25] K. H. Wang, L. C. Li, M. Shellaiah, and K. W. Sun, Sci. Rep., 2017, 7(1), 1-14.

[26] J. W. Lee, S. G. Kim, J. M. Yang, Y. Yang, and N. G. Park, APL Mater, 2019, 7(4), 041111.

[27] B. Yang, C. C. Brown, J. Huang, L. Collins, X. Sang, R. R. Unocic, S. Jesse, S. V. Kalinin, A. Belianinov, J. Jakowski, D. B. Geohegan, B. G. Sumpter, K. Xiao, and O. S. Ovchinnikova, Adv. Funct. Mater, 2017, 27(26), 1700749.

[28] O. Almora, I. Zarazua, E. Mas-Marza, I. Mora-Sero, J. Bisquert, and G. Garcia-Belmonte, J. Phys. Chem. Lett., 2015, 6(9), 1645-1652.

[29] C. Eames, J. M. Frost, P. R. F. Barnes, B. C. O’Regan, A. Walsh, and M. S. Islam, Nat. Commun., 2015, 6(1), $1-8$.

[30] J. M. Azpiroz, E. Mosconi, J. Bisquert, and F. De Angelis, Energy Environ. Sci., 2015, 8(7), 2118-2127.

[31] Y. Nah, O. Allam, H. S. Kim, J. I. Choi, I. S. Kim. J. Byun, S. O. Kim, S. S. Jang, and D. H. Kim, ACS Nano, 2021, 15(1), 1486-1496.

[32] G. Y. Kim, A. Senocrate, Y. Wang, D. and Moia, J. Maier, Angew. Chem. Int. Ed., 2021, 60, 820-826.

[33] J. Haruyama, K. Sodeyama, L. Han, and Y. Tateyama, J. Am. Chem. Soc., 2015, 137(32), 10048-10051.

[34] S. Meloni, T. Moehl, W. Tress, M. Franckeviius, M. Saliba, Y. H. Lee, P. Gao, M. K. Nazeeruddin, S. M. Zakeeruddin, U. Rothlisberger, and M. Graetzel, Nat. Commun., 2016, 7(1), 1-9.

[35] S. R. G. Balestra, J. M. Vicent-Luna, S. Calero, S. Tao, and J. A. Anta, J. Mater. Chem. A., 2020, 8(23), 1182411836. 